Ranny Nur Agustin ${ }^{1}$

Ria Novianti ${ }^{2}$

Enda Puspitasari ${ }^{3}$

\section{PENGARUH INTENSITAS PENGGUNAAN GADGET TERHADAP KEMAMPUAN MOTORIK KASAR ANAK USIA 4-5 TAHUN DI TK SE- KECAMATAN BANGKINANG KOTA KABUPATEN KAMPAR}

\begin{abstract}
Abstrak
Kemampuan motorik kasar terbentuk saat anak mulai memiliki koordinasi dan keseimbangan. Motorik kasar adalah kemampuan yang membutuhkan koordinasi sebagian besar bagian tubuh anak. Oleh karena itu, biasanya memerlukan tenaga karena dilakukan oleh otot-otot besar. Motorik kasar melibatkan aktivitas otot tangan, kaki, dan seluruh tubuh anak. Perkembangan motorik kasar pada anak usia dini perlu diberikan rangsangan berupa latihan sehingga anak lebih terampil dalam melakukan gerakan-gerakan. Jika anak banyak bergerak maka akan semakin banyak manfaat yang dapat diperoleh anak ketika ia makin terampil menguasai gerakan motoriknya. Oleh karena itu, anak yang cenderung terlalu bermain gadget tidak mendapat adanya rangsangan untuk fisik motorik, artinya perkembangan fisik motoriknya terhambat, karena terlalu sering bermain gadget. Penelitian ini bertujuan untuk mengetahui besarnya pengaruh intensitas penggunaan gadget terhadap kemampuan motorik kasar anak usia 4-5 tahun TK se-Kecamatan Bangkinang Kota Kabupaten Kampar. Analisis data yang digunakan pada penelitian ini menggunakan analisis regresi linier sederhana. Hasil penelitian menunjukkan bahwa ada hubungan yang signifikan antara intensitas menggunakan gadget dengan kemampuan motorik kasar siswa TK usia 4-5 Tahun se Kecamatan Bangkinang Kota, yaitu dibuktikan dengan nilai signifikansi p $0,00<0,05$, dan besarnya sumbangan intensitas menggunakan gadget terhadap kemampuan motorik kasar sebesar 7,2 \%.
\end{abstract}

Kata Kunci: Penggunaan Gadget, Motorik Kasar

\begin{abstract}
Gross motor skills are formed when children begin to have coordination and balance. Gross motor skills are skills that require the coordination of most parts of the child's body. Therefore, it usually requires strength because it is carried out by large muscles. Gross motor activities involve the activity of the muscles of the hands, feet and the whole body of the child. Gross motor development in early childhood needs to be given stimulation in the form of training so that children are more skilled in making movements. If the child moves a lot, the more benefits the child can get when he is more skilled at mastering motor movements. Therefore, children who tend to play gadgets too much do not get stimulation for their physical motor skills, meaning that their physical motor development is hampered, because they play gadgets too often. This study aims to determine the magnitude of the influence of the intensity of the use of gadgets on gross motor skills of children aged 4-5 years of kindergarten in Bangkinang District, Kampar District. Analysis of the data used in this study using simple linear regression analysis. The results showed that there was a significant relationship between the intensity of using gadgets and the gross motor skills of kindergarten students aged 4-5 years in Bangkinang Kota District, which is evidenced by a significance value of $\mathrm{p} 0.00<0.05$, and the magnitude of the contribution of intensity using gadgets to their abilities. gross motor skills of $7,2 \%$.
\end{abstract}

\footnotetext{
${ }^{1,2,3)}$ Program Studi Pendidikan Guru Pendidikan Anak Usia Dini, Fakukltas Keguruan dan Ilmu Pendidikan, Universitas Riau

Alamat email ria.novianti@lecturer.unri.ac.id
} 
Keywords: of Use of Gadgets, Gross Motor

\section{PENDAHULUAN}

Penggunaan gadget dengan durasi yang berlebihan sangat berpengaruh terhadap perkembangan anak. Intensitas penggunaan gadget dapat dilihat seberapa sering menggunakan gadget dalam sehari. Menurut Sari dan Mitsalia (2016), pemakaian gadget dikategorikan dengan intensitas tinggi jika menggunakan gadget dengan durasi lebih dari 120 menit /hari dan dalam sekali pemakaiannya berkisar $>75$ menit. Selain itu, dalam sehari bisa berkali - kali (lebih dari 3 kali pemakaian) pemakaian gadget dengan durasi 30 - 75 menit akan menimbulkan kecanduan dalam pemakaian gadget. Selanjutnya, penggunaan gadget dengan intensitas sedang jika menggunakan gadget dengan durasi lebih dari 40-60 menit /hari dan intensitas penggunaanan dalam sekali penggunaan $2-3 \mathrm{kali} / \mathrm{hari}$ setiap penggunaan.

Meningkatnya intensitas pengunaan gadget dikhawatirkan akan meningkatkan angka kecanduan gadget. Kecanduan gadget dapat meningkatkan prevalensi resiko gangguan pemusatan perhatian dan hiperaktivitas. (Ilga dan Ria,2020).

Anak yang menghabiskan sebagian waktu bermainnya hanya dengan bermain gadget, menyebabkan mereka menjadi anak-anak yang cenderung malas bergerak dan beraktivitas gerak. Anak-anak seperti ini akan lebih memilih menghabiskan waktunya dengan duduk di depan gadget dan menikmati berbagai fitur yang ada didalamnya. Anak yang seperti ini nantinya akan tumbuh dan berkembang menjadi anak yang obesitas/kegemukan. Mereka kurang menjalani aktifitas fisik dan kebiasaan sibuk menghabiskan makanan samba, bermain gadget. Jika hal ini sampai terjadi maka akan menghambat perkembangan motoriknya. Pada hakikatnya, anak yang hidup tanpa gadget akan menghabiskan sebagian waktunya dengan aktivitas motoriknya seperti melakukan gerakan-gerakan motorik kasar sederhana seperti berjalan, melompat, berjinjit dan juga berlari (Elfiadi, 2018).

Anak generasi alpha berada pada usia keemasan dimana periode ini perkembangan anak terjadi sangat pesat dan tak akan terulang lagi pada periode berikutnya. Aspek perkembangan kognitif, Bahasa, moral dan agama, fisik motorik dan sosial emosional yang terjadi pada usia ini akan menjadi dasar yang mempengaruhi dan menentukan perkembangan anak pada saat remaja dan dewasa. Mengingat pentingnya masa-masa keemasan ini, maka akan sangat baik bila semua stimulasi yang diberikan pada anak memiliki dampak positif bagi perkembangannnya (Ria,Hukmi \& Ilga, 2019).

Menurut Berk (dalam Suyadi, 2010) Motorik kasar adalah gerak anggota badan secara kasar atau keras. Semakin anak bertambah dewasa dan kuat tubuhnya, maka gaya geraknya semakin sempurna. Hal ini mengakibatkan tumbuh-kembang otot semakin membesar dan menguat. Dengan membesar dan menguatnya otot tersebut, keterampilan baru selalu bermunculan dan semakin bertambah kompleks.

Menurut (Sujiono Dkk, 2008) Motorik kasar adalah kemampuan yang membutuhkan koordinasi sebagian besar tubuh anak yang melibatkan aktivitas otot tangan, kaki, dan seluruh tubuh anak. Oleh karena itu, memerlukan tenaga karena dilakukan oleh otot-otot besar. Kemudian, gerakan motorik kasar juga memerlukan koordinasi kelompok otot-otot anak yang dapat membuat mereka dapat meloncat, memanjat, berlari, menaiki sepeda roda tiga, serta berdiri dengan satu kaki. Kemudian menurut Hadis ( dalam Sujiono Dkk, 2008) untuk merangsang motorik kasar anak dapat dengan dilakukan dengan melatih anak untuk meloncat, memanjat,berlari, berjinjit, berdiri diatas satu kaki, berjalan di papan titian dan sebagiannya.

Menurut (Aisyah, 2010.) masa anak-anak adalah masa yang sering disebut "masa ideal" untuk mempelajari keterampilan motorik. Ada beberapa alasan yang mendasari hal tersebut, yaitu Tubuh anak-anak lebih lentur dari pada tubuh remaja atau orang dewasa sehingga anakanak lebih mudah untuk menerima pelajaran untuk mengembangkan motoriknya, Anak belum banyak memiliki keterampilan yang akan berbenturan dengan keterampilan yang baru dipelajarinya maka bagi anak mempelajari keterampilan baru lebih mudah, Secara keseluruhan anak lebih berani pada waktu kecil dari pada ketika dia sudah besar. 
Pada perkembangan fisik-motorik, yang seharusnya anak menjadi pribadi yang aktif serta kreatif namun karena lebih asyik bermain dengan gadgetnya perkembangan tersebut menjadi terhambat, karena membuat anak menjadi malas dan lambat bergerak. Menurut Ameliola\&Nugraha ( dalam Warisyah, 2016) Penggunaan gadget dikalangan anak berdampak negative terhadap perkembangannya, dengan adanya kemudahan dalam mengakses berbagai media informasi dan teknologi, sehingga menyebabkan anak-anak menjadi malas bergerak dan beraktifitas. Mereka lebih memilih untuk bermain gadget dibandingkan dengan berinteraksi dengan dunia nyata.

\section{METODE}

Penelitian ini dilakukan di TK se- Kecamatan Bangkinang Kota Kabupaten Kampar pada bulan juni tahun 2020 sampai selesai. Jenis data yang digunakan dalam penelitian ini adalah data primer berupa kuesioner kepada obyek penelitian dan diisi secara langsung oleh yang responden dan data sekunder arsip yang dimiliki organisasi/instansi, studi pustaka, penelitian terdahulu, literatur, dan jurnal yang berhubungan dengan permasalahan yang diteliti. populasi dalam penelitian ini adalah anak-anak usia 4-5 tahun di TK se-Kecamatan Bangkinang Kota Kabupaten Kampar yang berjumlah 211 orang.

Pengumpulan data penelitian dilakukan dengan menggunakan kuesioner (angket). Analisis data yang digunakan dalam penelitian ini adalah analisis kuantitatif, merupakan suatu teknik analisa data yang menggunakan angka- angka agar pemecahan masalah dapat dihitung secara pasti. Alat analisis yang digunakan adalah regresi linear sederhana. Persamaan regresi linier sederhana dapat dirumuskan sebagai berikut :

$$
\mathrm{Y}=\alpha+\beta \mathrm{X}+e
$$

Keterangan :

$\mathrm{Y}=$ Kemampuan Motorik Kasar

$\alpha=$ Konstantanta

$\beta_{1}=$ Koefisien Regresi

$\mathrm{X}=$ Intensitas Penggunaan Gadget

$e=$ Error Term

\section{HASIL DAN PEMBAHASAN}

Data identitas responden diperoleh dari pengisian bagian awal lembar kuisioner, hasil pengisian kuesioner tersebut dijelaskan pada tabl berikut ini .

Tabel 1 :

Intensitas Bermain Gadget Siswa TK

Usia 4-5 Tahun se Kecamatan Bangkinang Kota Berdasarkan Frekuensi Jawaban Responden

\begin{tabular}{|l|c|c|c|c|c|c|}
\hline \multirow{2}{*}{ Kategori } & \multicolumn{2}{|c|}{ Indikator 1 } & \multicolumn{2}{c|}{ Indikator 2 } & \multicolumn{2}{c|}{ Indikator 3 } \\
\cline { 2 - 7 } & Frek & $\mathbf{\%}$ & Frek & \% & Frek & \% \\
\hline Sangat Tinggi & 68 & 49,28 & 63 & 45,65 & 49 & 35,51 \\
\hline Tinggi & 62 & 44,93 & 73 & 52,90 & 65 & 47,10 \\
\hline Sedang & 6 & 5,7 & 2 & 1,45 & 20 & 14,49 \\
\hline Kurang & - & - & - & - & 4 & 2,90 \\
\hline Sangat Kurang & - & - & - & - & - & - \\
\hline Jumlah & $\mathbf{1 3 8}$ & $\mathbf{1 0 0}$ & $\mathbf{1 3 8}$ & $\mathbf{1 0 0}$ & $\mathbf{1 3 8}$ & $\mathbf{1 0 0}$ \\
\hline
\end{tabular}

Berdasarkan tabel distribusi frekuensi tersebut, Diketahui bahwa hanya sedikit siswa yang frekuensi bermain gadgetnya rendah, yakni 4 orang untuk kategori kurang pada kecanduan bermain gadget, tergolong sedang sebanyak 20 orang untuk indikator kecanduan gadget, 2 orang untuk waktu menggunakan gadget dan 8 orang untuk frekuensi menggunakan gadget. 
Tabel 2 :

Kemampuan Motorik Kasar Siswa TK

Usia 4-5 Tahun se Kecamatan Bangkinang Kota Berdasarkan Frekuensi Jawaban Responden

\begin{tabular}{|l|c|c|}
\hline \multicolumn{1}{|c|}{ Kategori } & Frekuensi & Persentase \\
\hline Sangat Baik & 56 & 40,58 \\
\hline Baik & 53 & 38,41 \\
\hline Sedang & 30 & 21,74 \\
\hline Kurang Baik & - & \\
\hline Baik & - & $\mathbf{1 0 0}$ \\
\hline Jumlah & $\mathbf{1 3 8}$ & \\
\hline
\end{tabular}

Pada tabel 2, Diketahui bahwa kemampuan motorik menyebar hingga kategori sedang. Meskipun masih banyak kemampuan motorik kasar anak yang tergolong sangat baik namun harus tetap diwaspadai karena frekuensinya di bawah frekuensi anak yang intensitasnya bermain gadgetnya tinggi. Artinya, patut untuk diduga bahwa ada kecendrungan kemampuan motorik kasar anak untuk terus menurun, bila kebiasaan bermain gadget tidak dibatasi.

Tindakan selanjutnya, jika item pernyataan tidak valid, peneliti dapat mengganti item pertanyaan yang diajukan, namun juga harus dilakukan kembali pengujian, apakah valid atau tidak.

Tabel 3 :

Hasil Uji Validitas

\begin{tabular}{|l|c|c|c|c|}
\hline Variabel & Item & r hitung & r tabel & Keputusan \\
\hline \multirow{4}{*}{$\begin{array}{l}\text { Intensitas } \\
\text { Penggunaan }\end{array}$} & Item1 & 0,208 & 0,139 & Valid \\
\cline { 2 - 5 } Gadget (X) & Item2 & 0,300 & 0,139 & Valid \\
\cline { 2 - 5 } & Item3 & 0,349 & 0,139 & Valid \\
\cline { 2 - 5 } & Item4 & 0,315 & 0,139 & Valid \\
\cline { 2 - 5 } & Item5 & 0,378 & 0,139 & Valid \\
\cline { 2 - 5 } & Item6 & 0,366 & 0,139 & Valid \\
\cline { 2 - 5 } & Item7 & 0,325 & 0,139 & Valid \\
\cline { 2 - 5 } & Item8 & 0,265 & 0,139 & Valid \\
\cline { 2 - 5 } & Item9 & 0,307 & 0,139 & Valid \\
\cline { 2 - 5 } & Item10 & 0,384 & 0,139 & Valid \\
\cline { 2 - 5 } & Item11 & 0,431 & 0,139 & Valid \\
\hline \multirow{4}{*}{ Kemampuan } & Item12 & 0,225 & 0,139 & Valid \\
\cline { 2 - 5 } & Item1 & 0,562 & 0,139 & Valid \\
\cline { 2 - 5 } & Item2 & 0,633 & 0,139 & Valid \\
\cline { 2 - 5 } & Item3 & 0,589 & 0,139 & Valid \\
\cline { 2 - 5 } & Item4 & 0,565 & 0,139 & Valid \\
\cline { 2 - 5 } & Item5 & 0,685 & 0,139 & Valid \\
\cline { 2 - 5 } & Item6 & 0,682 & 0,139 & Valid \\
\cline { 2 - 5 } & Item7 & 0,590 & 0,139 & Valid \\
\hline & Item8 & 0,389 & 0,139 & Valid \\
\hline
\end{tabular}

Sumber : Data Olahan, 2021

Hasil uji validitas sebagaimana tercantum pada tabel 3 menunjukkan bahwa seluruh item pernyataan dinyatakan valid karena nilai $r$ hitung lebih besar dari pada $r$ tabel, dimana nilai $r$ tabel untuk $\mathrm{n}=138$ adalah sebesar 0,1396 (Riduwan dan Sunarto, 2012: 353). 
Tabel 4 :

Hasil Uji Reliabilitas

\begin{tabular}{|l|c|c|c|}
\hline \multicolumn{1}{|c|}{ Variabel } & $\begin{array}{c}\text { Jumlah } \\
\text { Item }\end{array}$ & $\begin{array}{c}\text { Cronbach } \\
\text { Alpha }\end{array}$ & Keterangan \\
\hline $\begin{array}{l}\text { Intensitas Penggunaan Gadget } \\
(\mathrm{X})\end{array}$ & 12 & 0,670 & Reliabel \\
\hline Kemampuan Motorik Kasar (Y) & 8 & 0,760 & Reliabel \\
\hline
\end{tabular}

Sumber : Data Olahan, 2021

Hasil pengujian untuk semua variabel diperoleh nilai alpha cronbach's di atas 0,6, ini berarti bahwa tingkat kehandalan dari butir-butir pertanyaan untuk variabel yang diteliti sudah baik.

Setelah melakukan uji validitas dan normalitas, uji prasyarat yang harus dipenuhi dalam analisis regresi linier sederhana adalah uji normalitas. Pengujian normalitas bertujuan untuk melihat apakah data yang digunakan mengikuti pola distribusi normal atau tidak. Uji normalitas ini dapat dilihat pada grafik normal P-P Plot sebagai berikut:

Gambar 1:

\section{Uji Normalitas}

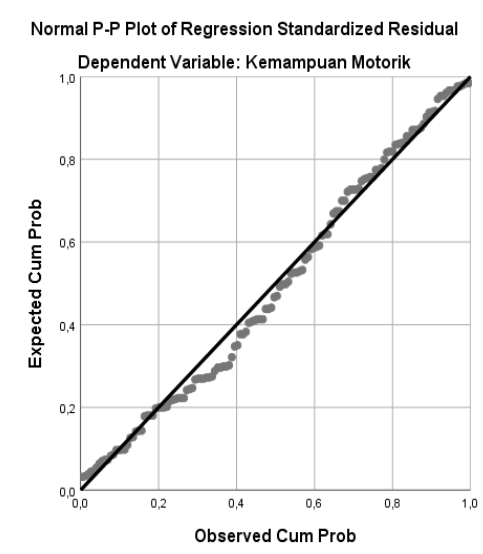

Pada gambar 1 dapat dilihat bahwa data menyebar di sekitar garis linier sehingga dapat dikatakan bahwa data berdistribusi normal.

Setelah pengujian kualitas data dilakukan dan didapatkan bahwa data tersebut valid, reliabel dan normal, maka selanjutnya dilakukan uji linearitas bertujuan untuk mengetahui apakah dua variabel mempunyai hubungan yang linear atau tidak secara signifikan.

Tabel 5 :

RANGKUMAN HASIL UJI LINIERITAS

\begin{tabular}{|l|c|c|c|}
\hline \multicolumn{1}{|c|}{ Hubungan } & $\boldsymbol{p}$ & Sig. & Keterangan \\
\hline $\begin{array}{l}\text { Intensitas menggunakan gadget } \\
\text { dengan kemampuan motorik } \\
\text { kasar }\end{array}$ & 0,730 & 0,05 & Linier \\
\hline
\end{tabular}

Dari tabel, terlihat bahwa nilai signifikansi (p) $0,730>0,05$. Jadi, hubungan variabel bebas dengan variabel terikatnya dinyatakan linear.

Hasil uji hipotesis dalam penelitian ini berbunyi "Ada hubungan yang signifikan antara intensitas penggunaan gadget dengan kemampuan motorik kasar siswa TK usia 4-5 Tahun se Kecamatan Bangkinang Kota". Hasil uji hipotesis dengan menggunakan analisis korelasi dapat dilihat pada tabel 6 berikut ini. 
Tabel 6 :

KoEFISIEN KoRELASI INTENSITAS PENGgUNAAN GAdGET DENGAN KEMAMPUAN MOTORIK KASAR SISWA TK USIA 4-5 TAHUN

SE KECAMATAN BANGKINANG KOTA

\begin{tabular}{|r|c|c|c|c|}
\hline Korelasi & $\mathbf{r}$ hitung & $\mathbf{r}$ tabel $(\mathbf{d f} \mathbf{1 3 8 ; 0 , 0 5})$ & Sig. & Keterangan \\
\hline $\mathrm{XY}$ & $-0,269$ & 0,1396 & 0,001 & Signifikan \\
\hline
\end{tabular}

Berdasarkan hasil analisis tersebut di atas diperoleh koefisien intensitas menggunakan gadget dengan kemampuan motorik kasar sebesar -0,269 (berhubungan negatif), artinya semakin tinggi intensitas menggunakan gadget, maka semakin rendah kemampuan motorik kasarnya. Uji keberartian koefisien korelasi tersebut dilakukan dengan cara mengonsultasi harga $\mathrm{r}$ hitung dengan $\mathrm{r}$ tabel, pada $\alpha=5 \%$ dengan $\mathrm{n}=138$ diperoleh $\mathrm{r}$ tabel sebesar 0,1396 . Nilai signifikansi p $0,000<0,05$, berarti korelasi tersebut signifikan. H1 yang berbunyi "Ada hubungan yang signifikan antara intensitas menggunakan gadget dengan kemampuan motorik kasar siswa TK usia 4-5 Tahun se Kecamatan Bangkinang Kota, diterima.

Besarnya pengaruh (sumbangan efektif) intensitas menggunakan gadgetdengan kemampuan motorik kasar diketahui dengan cara nilai $\mathrm{R}$ (Koefisien Determinasi) $=\mathrm{r} 2 \times 100 \%$. Nilai $\mathrm{r} 2$ sebesar $0,072 \times 100 \%$, sehingga besarnya sumbangan sebesar 7,2 \%, sedangkan sisanya sebesar $92,80 \%$ dipengaruhi oleh faktor lain yang tidak diteliti dalam penelitian ini.

Hasil penelitian menunjukkan bahwa ada hubungan yang signifikan antara intensitas menggunakan gadget dengan kemampuan motorik kasar siswa TK usia 4-5 Tahun se Kecamatan Bangkinang Kota, yaitu dibuktikan dengan nilai signifikansi p 0,00<0,05, dan besarnya sumbangan intensitas menggunakan gadget terhadap kemampuan motorik kasar sebesar 7,2 \%. Hubungan antara intensitas menggunakan gadget dengan kemampuan motorik kasar siswa bernilai negatif, artinya jika intensitas menggunakan gadget yang dilakukan semakin tinggi, maka kemampuan motorik kasar siswa akan semakin kurang/rendah. Sesuai dengan pendapat Kurniawan (2017: 99) bahwa tingginya intensitas menggunakan gadget memberikan berbagai macam dampak atau pengaruh tidak baik itu terhadap fisik maupun psikis individu. Dampak fisik dapat berupa kelelahan pada anggota tubuh karena terlalu lama bermain gadget yang menyebabkan kesehatan badan menurun sehingga mudah sakit.

Kemudian, pada penelitian ini uji hipotesis membuktikan bahwa intensitas penggunaan gadget berpengaruh signifikan terhadap kemampuan motorik kasar anak, dimana p 0,001<0,05. Menurut Sujiono (2014: 68) bahwa lingkungan juga mempengaruhi perkembangan motorik kasar. Hal ini dikarenakan adanya stimulasi dari lingkungan, misalnya sarana dan prasarana yang menarik maka anak akan bergerak menuju ke arah benda tersebut. Demikian juga dengan pelaksanaan kegiatan pembelajaran yang menarik, maka anak akan tertarik untuk mengikuti pembelajaran motorik di kelas ataupun di luar kelas. Pendapat tersebut sejalan dengan Rahyubi (2012: 226) perkembangan motorik seorang individu berjalan optimal jika lingkungan tempatnya beraktivitas mendukung dan kondusif.

Kemampuan motorik kasar juga dipengaruhi oleh faktor mekanik dan fisik. Faktor mekanik terdiri dari beberapa unsur, diantaranya: (1) faktor keseimbangan yang terdiri dari: pusat gaya, garis gaya dan dasar penyokong badan; (2) faktor pemberi daya, yang terdiri dari: gerak yang lamban, percepatan, aktivitas / reaksi; (3) faktor penerima daya yang tediri dari: daerah permukaan dan jarak; (4) kemampuan lokomotor, terdiri dari: fase refleks, fase belum sempurna, fase dasar, fase spesialisasi; (5) kemampuan manipulatif; (6) kemapuan yang stabil. Sedangkan factor fisik terdiri dari unsur-unsur diantaranya: (1) faktor kesegaran jasamani yang terdiri dari: kekuatan, daya tahan aerobik, daya tahan, kelentukan, komposisi tubuh; (2) faktor kesegaran gerak (motor fitness) terdiri dari: kecepatan, kelincahan, koordinasi, keseimbangan, dan daya ledak (power) (Mutohir, dalam Yudanto, 2005: 35). Pendapat lain diungkapkan Sukintaka (Primasoni \& Yudanto, 2011: 41) menyatakan bahwa berkembangnya kemampuan motorik kasar sangat ditentukan oleh partumbuhan dan perkembangan. Kedua faktor ini rnasih harus didukung oleh latihan yang sesuai dengan tingkat kernatangan anak, dan gizi yang baik.

Hasil penelitian ini didukung oleh penelitian Muhammad Lukman Irvani (2020) yang menyimpulkan bahwa terdapat hubungan negatif penggunaan bermain game online terhadap 
kemampuan motorik kasar siswa. Penelitian lainnya yang senada juga yakni oleh penelitian Nuhan (2016) menyatakan bahwa siswa yang kecanduan bermain game mengalami berbagai masalah terutama pada perilaku akademis. Perilaku akademis seperti tidak mengerjakan tugas, malas mengikuti kegiatan belajar dan tidak adanya konsentrasi pada diri siswa (5). Bermain game $\leq 3$ jam dan $>3$ jam per hari dapat mempengaruhi otak sehingga berdampak pada kerja dan fungsi otak itu sendiri yang berkaitan dengan kognitif atau kecerdasan. Penelitian Palaus et al (2017) menyatakan bermain video game dapat mengubah cara kerja otak dan strukturnya. Otak yang bermain game dapat mempertahankan perhatian atau konsentrasi serta meningkatkan kemampuan kognitif atau kecerdasan. Namun jika bermain game dengan berlebihan dapat menimbulkan dampak negatif terhadap otak.

Penggunaan gadget yang berlebihan secara umum dapat mempengaruhi pertumbuhan dan perkembangan balita. Oleh karena itu, orang tua mempunyai peran aktif dalam membatasi anakanak dalam menggunakan gadget. Hal ini dilakukan untuk mencegah anak menjadi ketergantungan dengan gadget dan anak bisa lebih sering bermain bersama teman-teman seusianya. Selain itu, orang tua juga harus selalu mengawasi anak-anak ketika menggunakan gadget. Penggunaan gadget pada anak-anak dengan pembatasan dan pengawasan penuh dari orang tua dapat memberikan dampak positif pada anak-anak, diantaranya adalah menunjang pengetahuan, mengembangkan kreativitas, dan bereksplorasi mengembangkan apa yang sudah ada dan menemukan banyak peluang untuk menghasilkan temuan yang lebih baru (Pratama H.C., 2012). Selain itu variasi dari aplikasi yang edukatif bisa meningkatkan motivasi dan minat belajar anak (Sugianto V.J., 2015).

Gabbard (dalam Yudanto, 2011: 109) menyatakan bahwa dalam memilih sebuah permainan, perlu memperhatikan poin-poin yang harus diterapkan. Poin- poin tersebut diantaranya: 1) permainan harus bersifat menyenangkan, 2) permainan harus menyediakan aktivitas untuk semua anak secara maksimal, 3) meningkatkan pengembangan keterampilan gerak yang dibutuhkan, dan atau mengembangkan serta memilhara kebugaran, dan 4) mencakup keseluruhan peserta dan bukan pengurangan peserta permainan. Gabbard (dalam Yudanto, 2011: 109) menyatakan bahwa diperlukan beberapa tambahan sebagai petunjuk dan pertimbangan dalam memilih permainan, yang diantaranya: 1) penggunaan kemajuan permainan, dari bentuk permainan yang kecil kemudian ke sebuah tim permainan, 2) ketika melakukan pemilihan permainan, diperlukan peningkatan/ kemajuan jumlah dan kompleksitas peraturan serta strategi, 3) menggunakan situasi permainan untuk evaluasi dan meningkatkan perilaku afektif dan juga kecakapan keterampilan gerak, 4) keamanan harus sebagai dasar yang harus dipertimbangkan, 5) tempatkan anak ke dalam sebuah formasi dan buatlah petunjuk bila dimungkinkan, 6) meskipun partisipasi sangat ditekankan, jika partisipasi anak perlu dikurangi, disarankan hanya hanya satu atau dua putaran, dan 7) hindari penekanan yang berlebihan dalam sebuah kompetisi. Lutan (dalam Yudanto, 2005: 35) menyatakan bahwa kemampuan motorik kasar dikatakan sebagai kualitas kemampuan seseorang yang dapat mempermudah dalam melakukan keterampilan gerak, kemampuan motorik kasar juga merupakan kualitas umum yang dapat ditingkatkan melalui latihan. Lebih lanjut dijelaskan bahwa kemampuan motorik kasar yang berarti kualitas hasil gerak individu dalam melakukan gerak, baik yang bukan gerak olahraga maupun dalam olahraga atau kematangan keterampilan motorik. Yudanto (2005: 35) menyatakan bahwa seseorang yang memiliki kemampuan motorik kasar yang tinggi diduga akan lebih baik dan berhasil dalam melakukan berbagai tugas keterampilan dibandingkan seseorang yang memiliki kemampuan motorik kasar rendah. Kemampuan motorik kasar yang dimiliki seseorang berbeda-beda dan terganrtung kepada banyaknya pengalaman gerakan yang dikuasai.

Kesiapan belajar anak penting untuk didampingi agar tidak terjadi kegagalan di bidang prestasi akademik dan lingkungan sosialnya. Salah satu bentuk kesiapan belajar pada anak ditandai dengan kematangan dalam pengelolaan aktivitas motorik, hal ini sejalan dengan pernyataan Heri Rahyubi (2012) bahwa penguasaan motorik yang baik bisa didayagunakan oleh seseorang untuk meraih prestasi bidang olahraga, seni, dan berbagai profesi lainnya. Sejatinya anak usia dini adalah individu yang sedang pada fase mengalami tumbuh kembang, David L.Gallahue (2011) mendefinisikan pertumbuhan fisik adalah perubahan yang ditandai dengan peningkatan tinggi badan, berat badan, dan massa otot. menunjang agar pertumbuhan fisik anak 
dapat optimal, organisasi kesehatan dunia, World Health Organisation (WHO) (2010) merekomendasikan jumlah waktu minimal untuk anak-anak beraktifitas fisik adalah 60 menit setiap hari dengan intensitas sedang hingga tinggi. Berdasarkan pernyataan tersebut dapat disimpulkan bahwa pentingnya kebutuhan akan aktifitas fisik untuk dilakukan guna mendapatkan generasi yang paripurna secara jasmani dan rohani, optimal dalam Pertumbuhan dan perkembangannya. Sehingga jika pola interaksi anak dan teknologi layar semakin tinggi maka secara otomatis membatasi aktivitas motoriknya sehingga sedikit sekali stimulasi motorik yang didapatkan. American academi of pediatric (2001) merekomendasikanaktivitas penggunaan media berbasis layar tidak lebih dari satu hingga dua jam per hari.

\section{UCAPAN TERIMA KASIH}

Tim peneliti mengucapkan terima kasih kepada Universitas Riau dan Program Studi Pendidikan Guru Pendidikan Anak Usia Dini yang telah memberi dukungan terhadap terlaksananya penelitian ini. Tim peneliti juga mengucapkan terima kasih kepada Pengelola Jurnal Review Pendidikan dan Pengejaran (JRPP) yang telah memberi review dan masukan atas terbitnya artikel ini.

\section{SIMPULAN}

Berdasarkan hasil analisis data, deskripsi, pengujian hasil penelitian, dan pembahasan, dapat diambil kesimpulan bahwa terdapat hubungan yang signifikan antara intensitas menggunakan gadget dengan kemampuan motorik siswa TK usia 4-5 Tahun se Kecamatan Bangkinang Kota, dengan $r_{x . y}=-0,269$ nilai signifikansi p $0,000<0,05$. Hubungan antara intensitas bermain menggunakan gadget dengan kemampuan motorik siswa bernilai negatif, artinya jika intensitas menggunakan gadget semakin tinggi, maka kemampuan motorik siswa akan semakin kurang/rendah.

\section{DAFTAR PUSTAKA}

Aisyah, S. 2010. (n.d.). dkk.(2010). Perkembangan Dan Konsep Dasar Pengembangan Anak Usia Dini.

David L Gallahue. 2011. Developmental Physical Education For Today's Children. United States Of America; Brown And Benchmark Publishing.

Elfiadi. (2018). Dampak Gadget Terhadap Perkembangan. Itqan, 9(2), 97-110.

Heri Rahyubi. (2012). Teori-teori Belajar dan Aplikasi Pembelajaran Motorik. Bandung: Nusa media.

Irvani, Muhammad L, (2020). Hubungan intensitas bermain game onilne dengan kemampuan motorik kasar siswa kelas VII di SMP Negeri 4 Ngaglik. Skripsi. Tidak Diterbitkan.

I Maria, R Novianti.(2020). The Effects of Using Gadgets during the Covid-19 Pandemic on Children's Behaviour. Ațāluna: Journal of Islamic Early Childhood Education. 3 (2), 74-81

Novianti, R., Hukmi, H., \& Maria, I. (2019). (n.d.). GENERASI ALPHA-TUMBUH DENGAN GADGET DALAM GENGGAMAN. Jurnal Educhild: Pendidikan Dan Sosial, 8(2), $65-70$.

R Novianti, F Febrialismanto, E Puspitasari, H Hukmi.(2020). Meningkatkan pengetahuan orang tua dalam mendidik anak di era digital di Kecamatan Koto Gasib Kabupaten Siak Provinsi Riau. Riau Journal of Empowerment. 3 (3), 183-190.

R Novianti, M Garzia (2020). Penggunaan Gadget pada Anak Usia Dini; Tantangan Baru Orang Tua Milenial. Jurnal Obsesi: Jurnal Pendidikan Anak Usia Dini. 4 (2), 1000-1010

Mulyasa, H. E. (2012). Manajemen Paud. Bandung: Remaja Rosdakarya. Pratama, H. C. 2012. Cyber Smart Parenting. Bandung : PT. Visi Anugerah Indonesia.

Sari, P dan Mitsalia A. A. 2016. Pengaruh Penggunaan Gadget Terhadap Personal Sosial Anak Usia Pra Sekolah di Tkit Al Mukmin. Jurnal Profesi 13 (2) : 73 - 77.

Sujiono Dkk, B. (2008). Metode Pengembangan Fisik. Jakarta: Universitas Terbuka 
Sugianto, Vincent J., W. H. Prayanto, and Hen Dian Yudani. "Perancangan Board Game Mengenai Bahaya Radiasi Gadget Terhadap Anak". Jurnal DKV Adiwarna 1 (2015): 15.

Wijanarko, I. J., \& Setiawati, I. E. (2016). Ayah Ibu Baik. Happy Holy Kids.

World Health Organisation. (2010). Global Recommendations on Physical Activity for Health . Switzerland; WHO press. 